\title{
Consecuencias previsibles de una independencia unilateral de Cataluña
}

La antidemocrática seudoconsulta del pasado 9 de noviembre en Cataluña, a pesar de haber sido un acto ilegal, no debe menospreciarse como hecho histórico. Ha dejado claras al menos tres cosas: la primera, que el bloque soberanista está consiguiendo dividir a la sociedad catalana entre buenos y malos catalanes; la segunda, que no respeta la Constitución, si bien nunca lo hizo; y la tercera, que la Generalitat ha usado técnicas que rememoran los referéndum franquistas, aunque los pucherazos de antaño se han sustituido ahora por el todo vale para la causa: rebaja de la edad legal de voto, barra libre para extranjeros, dilapidación de recursos públicos en su organización, implicación directa de líderes políticos presidiendo mesas, etc.

Resulta poco comprensible que los genuinos representantes de los intereses de la burguesía catalana, que solo busca su privilegio, hayan conseguido arrastrar a partidos de izquierda que teóricamente debieran representar a la clase trabajadora, mayoritariamente inmigrante (del extranjero y de otras comunidades autónomas), que serían las primeras víctimas de la secesión. La raíz del problema está en la crisis económica, en la pésima gestión de los gobiernos de la Generalitat y en la falta de respuesta del gobierno español y de la sociedad catalana ante la manipulación, sin límites y en todos los frentes, que utilizan los nacionalistas para eludir su incapacidad para resolver los problemas catalanes.

Tras la farsa del 9 de noviembre, el diálogo y el entendimiento entre el gobierno central y el autonómico se ha hecho mucho más difícil y complejo. La amenaza de que la única alternativa que les queda a los soberanistas es la de declarar unilateralmente la independencia, si en las próximas eleccio- 
nes autonómicas cuentan con una mayoría suficiente, es una espada de Damocles que pende sobre toda la sociedad española. Una declaración unilateral de independencia implicaría apostar por el peor de los escenarios posibles para el futuro de Cataluña, por lo no se va a producir; pero si a pesar de todo ocurriese, las consecuencias de una irresponsabilidad de este tipo llevaría a la ruina económica al nuevo Estado catalán y plantearía un gravísimo problema a España e incluso a la Unión. Veamos por qué.

Tras los fastos de la celebración de la independencia, el primer acuerdo del nuevo gobierno del Estado catalán, con toda probabilidad, sería decretar una amnistía general con el fin de enmascarar su verdadero objetivo: la amnistía fiscal. Como un nuevo Estado debe nacer impoluto, se alegaría la inaplicabilidad de la legislación española que históricamente ha pisoteado a Cataluña. Con la amnistía fiscal se tratarían de tapar los muchos y graves casos de corrupción que pesan sobre los nacionalistas, comenzando por Pujol y su familia. El sobrevenido soberanismo de CiU no es ajeno a este hecho y a toda la corruptela que se ha generado en su entorno.

Desde el mismo momento de la independencia, Cataluña dejaría de formar parte de la Unión Europea y pasaría a ser un país tercero. Ello implicaría, entre otras cosas, su salida del mercado interior comunitario que aplicaría el arancel aduanero común y las medidas de carácter no arancelario; y también se suprimirían la libre circulación de servicios, de personas y, previsiblemente, de capitales. Cataluña quedaría excluida de las restantes políticas de la Unión, entre ellas de la unión económica y monetaria, con lo cual el euro pasaría a tener la consideración de divisa (moneda extranjera); igualmente dejaría de formar parte del espacio de Schengen -con consecuencias muy graves para los aeropuertos catalanes y para el turismo- y tal vez sus ciudadanos vendrían obligados, al menos por unos años, a necesitar de visado para acceder a la Unión.

Al elegir el camino de la independencia unilateral, en reclamación del principio de autodeterminación que no es reconocido por ninguna constitución democrática, Cataluña no conseguiría el reconocimiento internacional de prácticamente ningún Estado importante. No podría formar parte de 
la ONU y de sus agencias especializadas, entre ellas el Fondo Monetario Internacional (FMI) y Banco Mundial, lo que le impediría acceder a sus préstamos. De manera que Cataluña pasaría a engrosar el limbo en el que actualmente se encuentran conocidos Estados que también eligieron en el pasado reciente el camino de la independencia unilateral (aunque por caminos menos pacíficos que por los que transitaría Cataluña): Abjasia, Osetia del Sur, Somalilandia, Transnistria, etc.

En la actualidad, la Generalitat catalana está técnicamente quebrada. Su sobrevivencia depende de los recursos que le preste o avale el Estado porque nadie le concede un crédito, ni siquiera los abnegados nacionalistas a través de los famosos bonos patrióticos tan de moda en años pasados (los últimos tuvieron que ser liquidados por el Estado en abril de 2014 a través del fondo de liquidez autonómica-FLA-). Al cierre del ejercicio de 2013, Generalitat acumulaba una deuda pública de 57.146 millones de euros a la que habría que agregar otros 170.899 millones que le correspondería participar en la total de la española según su peso en el PIB total $(18,8 \%)$; de manera que el nuevo Estado nacería -tomando como referencia el citado año de 2013- con una deuda pública por un total de 228.044 millones de euros (al que habría que añadir el de las empresas públicas), equivalentes al $118,4 \%$ de su PIB, a la que naturalmente no podría hacer frente y tendría que declararse insolvente.

Las empresas catalanas dependientes de la exportación a otras regiones españolas y al resto del mundo, huirían en masa, comenzando por las muy autóctonas Banco Sabadell y Caixabank, para mantenerse al resguardo del euro y del Banco Central Europeo. La deslocalización de empresas, comenzando por las multinacionales, originaría un gravísimo problema económico y social.

Cataluña trataría de conceder a sus ciudadanos la doble nacionalidad (española y catalana), que España no aceptaría. Podría ocurrir que más de la mitad de la población del nuevo Estado optase por la nacionalidad española, lo que le privaría del derecho al voto, así como de otros derechos políticos y sociales en Cataluña. En tal supuesto, el conflicto social que se produciría es imprevisible y con toda seguridad se originaría una salida en masa de población de Cataluña. 
En fin, Cataluña pasaría, por muchos años, a formar parte de los países subdesarrollados, ya que se prevé que su PIB descendería en no menos del $20 \%$ de su actual nivel y con muy escasas oportunidades de recuperación, puesto que no podría ser rescatado por la Unión Europea y también tendría cegadas las líneas de crédito del FMI. Las repercusiones para España también serían muy graves: perdería de forma directa cerca de la quinta parte de su PIB y su DP superaría con creces el 100\% del PIB; en este clima de incertidumbre, la prima de riesgo se dispararía a cotas tan elevadas que probablemente requeriría de un rescate de la Unión.

Para restañar las heridas originadas y recuperar la situación actual, Cataluña necesitaría no menos de 30 años para volver a la Unión: España y otros socios vetarían su entrada. Mientras tanto, Cataluña podría optar por incorporarse al Espacio Económico Europeo o intentar algún acuerdo de asociación con la Unión a través de la Política de Vecindad, pero tampoco estas vías serían fáciles ni ágiles y mucho menos si su pretensión fuese la de convertirse en paraíso fiscal. Elegir la independencia unilateral -que está prohibida por el Tratado de Lisboa- es optar por el peor de los caminos posibles: Cataluña no solo se separaría de España, que en otras circunstancias históricas no hubiera tenido gran coste, pero hacerlo de la Unión Europea y por las bravas, tiene un precio muy alto. Por ello, mantengo que Cataluña no elegirá esa vía, porque no tiene dónde ir, salvo al limbo internacional y al abismo económico. 